\title{
Depression-related anterior cingulate prefrontal resting state connectivity normalizes following cognitive behavioral therapy - CORRIGENDUM
}

\section{Corrigendum}

Cite this article: Pantazatos SP, Yttredahl A, Rubin-Falcone $\mathrm{H}$, Kishon R, Oquendo MA, Mann JJ, Miller JM (2020). Depression-related anterior cingulate prefrontal resting state connectivity normalizes following cognitive behavioral therapy - CORRIGENDUM. European Psychiatry, 63(1), e66, 1

https://doi.org/10.1192/j.eurpsy.2020.61

\section{Author for correspondence:}

Jeffrey Miller,

E-mail:jm2233@cumc.columbia.edu

Spiro P. Pantazatos,

E-mail: spiropan@gmail.com

\section{Spiro P. Pantazatos ${ }^{1,2 \star}$, Ashley Yttredahl ${ }^{1,2}$ (1), Harry Rubin-Falcone ${ }^{2,3}$,} Ronit Kishon ${ }^{2}$, Maria A. Oquendo ${ }^{4}$, J. John Mann ${ }^{1,2}$ and Jeffrey M. Miller ${ }^{1,2}$

${ }^{1}$ Molecular Imaging and Neuropathology, New York State Psychiatric Institute, New York, New York, USA; ${ }^{2}$ Department of Psychiatry, Columbia University Irving Medical Center, New York, New York, USA; ${ }^{3}$ Department of Electrical Engineering and Computer Science, University of Michigan, Ann Arbor, Michigan, USA and ${ }^{4}$ Department of Psychiatry, Perelman School of Medicine, University of Pennsylvania, Philadelphia, Pennsylvania, USA

doi: 10.1192/j.eurpsy.2020.34, Published online by Cambridge University Press : 30 April 2020

In the aforementioned article, the incorrect corresponding author was published; this has since been updated. The authors apologize for this error.

\section{Reference}

Pantazatos SP, Yttredahl A, Rubin-Falcone H, Kishon R, Oquendo MA, John Mann J, Miller JM. Depressionrelated anterior cingulate prefrontal resting state connectivity normalizes following cognitive behavioral therapy. Eur Psychiatry. 2020;63(1):e37. doi: 10.1192/j.eurpsy.2020.34. (c) The Author(s) 2020. Published by Cambridge University Press on behalf of the European Psychiatric Association. This is an Open Access article, distributed under the terms of the Creative Commons Attribution licence (http:// creativecommons.org/licenses/by/4.0/), which permits unrestricted re-use, distribution, and reproduction in any medium, provided the original work is properly cited. 